\title{
Erratum to: Comparative study on the environmental impact assessment of golf course development between Korea and China
}

\author{
Futoshi Nakamura
}

Published online: 19 November 2009

(C) International Consortium of Landscape and Ecological Engineering and Springer 2009

Erratum to: Landscape Ecol Eng (2006) 2:21-29 DOI 10.1007/s11355-006-0034-4

The editors of the journal Landscape and Ecological Engineering hereby retract the article "Comparative study on the environmental impact assessment of golf course development between Korea and China" by Jaeyong Choi and Young Han Kwon, which appeared in Landscape Ecol Eng (2006) 2:21-29. The article is being retracted because it contained the same research data that were used in the article "Comparative Study on the Environmental Impact
Assessment Items and Implementation on Golf Course Development between Korea and China" by Jae-yong Choi published in the Journal of the Korean Society for Environmental Restoration and Revegetation Technology (2004) 7(4):89-97.

Duplicate or redundant publication is a serious violation of scientific practice, causing damage to a journal. Please be reminded that it is an author's absolute responsibility to strictly comply with rigorous scientific and professional standards when submitting a manuscript for publication.

The online version of the original article can be found under doi:10.1007/s11355-006-0034-4.

F. Nakamura $(\square)$

Graduate School of Agriculture, Hokkaido University,

Sapporo 060-8589, Japan

e-mail: nakaf@for.agr.hokudai.ac.jp 